\title{
La reforma del Estado y el acceso de los pueblos indios a los medios de comunicación
}

\author{
JaVIer Esteinou Madrid* \\ Margarita Loera Chávez y Peniche**
}

\begin{abstract}
The uprising of the Zapatista National Liberation Army (Ejército Zapatista de Liberación Nacional) on January first, 1994 not only stated demands related to justice, peace, dignity and recognition of the indian communities basic rights, but also their access to collective communication media. For that reason, the point number 9 of San Andrés Larrainzar Agreements and the seventh clause of the Legal Iniciative of Indian Rights and Culture officially stated that the Mexican state had recognized that "indian people are entitled to free determination and autonomy, as a part of the Mexican state [...] to acquire, operate and administrate their own communication media". However, in spite of this political recognition, the agreements contained within both law iniciatives sent to the Legislative Power were deceitful and non sufficient to achieve a substantial change in the issue, and consequently, things remained unaltered.
\end{abstract}

Keywords: access to collective communication media, Zapatista National Liberation Army, indigenous culture.

\section{Resumen}

El levantamiento del Ejército Zapatista de Liberación Nacional el 1 de enero de 1994 ha planteado en los últimos siete años que las comunidades indígenas, además de demandar justicia, paz, dignidad y reivindicación de sus derechos básicos, también exigieran acceso a los medios colectivos de comunicación. Es por ello que el punto 9 de los Acuerdos de San Andrés Larráinzar y la Iniciativa de Ley de Reforma de Cultura y Derechos Indígenas, en su inciso 7, formularon oficialmente que el Estado mexicano reconocía que "los pueblos indígenas tienen el derecho a la libre determinación y a la autonomía, como parte del Estado mexicano [...] para adquirir, operar y administrar sus propios medios de comunicación”. No obstante estos reconocimientos políticos, los acuerdos pactados en ambas iniciativas de Ley enviadas al Poder Legislativo fueron engañosos e insuficientes para lograr un cambio sustancial en esta materia, y en consecuencia, todo permaneció igual.

Palabras clave: acceso a medios colectivos de comunicación, Ejército Zapatista de Liberación Nacional, cultura indígena.

* Universidad Autónoma Metropolitana, Unidad Xochimilco. Correo-e: jesteino@cueyatl.uam.mx

** Instituto Nacional de Antropología e Historia. Correo-e: magaloera@yahoo.com.mx 


\section{Medios de comunicación y participación social}

El surgimiento de los medios de información y sus nuevas capacidades tecnológico-materiales que conquistaron a México a lo largo del siglo Xx y lo que va del XXI -como son su amplia cobertura informativa, gran penetración mental, rápida capacidad de difusión, enorme versatilidad semiótica, gran perfeccionamiento tecnológico, etc.- se han convertido en el centro del poder contemporáneo de nuestra nación. Después de haber sido instrumentos de difusión relevantes en el México de 1920 y de convertirse en el cuarto poder político a partir de 1960 como corresponsables del poder, en la década de los años 90 se han transformado en el vértice del actual poder. Es decir, ya no sólo son instituciones importantes o el cuarto poder, sino que ahora son el primer poder que existe en nuestra sociedad.

De esta forma, frente a la tradicional acción de los sistemas escolar y religioso en nuestro país, los medios se han convertido en la principal red cultural y educativa capaz de cambiar con mayor rapidez y agilidad los valores, actitudes, hábitos y conductas de los receptores. En una idea, dirigen la cultura cotidiana en cada periodo histórico y social. Los medios se han transformado en los principales mediadores culturales, a través de los cuales se articula ideológicamente a nuestra sociedad, convirtiéndose en las principales instituciones colectivas organizadoras de la historia y la vida moderna de México.

En este sentido, la construcción o destrucción de la realidad masiva cotidiana, es decir, la definición de lo que existe o no existe, de lo que es bueno o es malo, de lo que hay por recordar u olvidar, de lo que es importante o no, de lo que es verdad o mentira, de lo que es visible o invisible, de lo que son valores o antivalores, de lo que es la opinión pública o de lo que no lo es, de lo que es virtuoso o no, de lo que hay por hablar o silenciar, de lo que hay por admirar o rechazar, de lo que es el éxito o el fracaso, se elabora cada vez más, especialmente en las grandes ciudades, desde los medios colectivos de difusión.

Pese a que los medios de información se han convertido en el primer poder en México, tradicionalmente el surgimiento y aprovechamiento de éstos ha surgido calcando la estructura y dinámica, económica y política de nuestra sociedad. Así, los procesos masivos de comunicación no han emergido en espacios neutros o independientes, sino que han cobrado vida vinculados a las necesidades de existencia y reproducción de nuestra sociedad 
capitalista en vías, primero de industrialización, y ahora de globalización.

Esta tendencia ha ocasionado, entre otros fenómenos comunicativos, que la estructura de medios de comunicación en México se encuentre altamente concentrada y centralizada. Dentro de este marco histórico de concentración informativa, el margen de participación de los movimientos sociales a través de los medios de comunicación, y por lo tanto, la capacidad de ejercer su derecho a la información, han sido sumamente estrechos, sin llegar a ser un fenómeno monolítico. El margen de acción ciudadana ha oscilado entre una gama de intervenciones que varían desde los canales escritos hasta los electrónicos. Así, encontramos que las vías a través de las cuales los movimientos sociales mexicanos han participado con mayor fuerza, desde principios de siglo hasta la fecha para expresar sus intereses y demandas y aplicar su derecho a la comunicación se concentra con mayor peso en los medios impresos y se cierra casi por completo en los canales electrónicos, particularmente audiovisuales, lo que crea una profunda crisis en el ejercicio del derecho a la información y a la comunicación.

No obstante que en la actualidad la sociedad mexicana ya ha alcanzado los cien millones de habitantes, y pese a que en última instancia los grupos básicos que sostienen a nuestra nación son los que financian el funcionamiento de la televisión, confirmamos que la mayor parte de estos sectores básicos no tienen acceso a la participación en este medio de comunicación para exponer colectivamente sus necesidades e incorporarse a los procesos de gestión pública del país. Por ello podemos afirmar que, salvo algunas excepciones, la información televisiva que ha producido y difundido el actual modelo de televisión privada y algunos modelos públicos no ha permitido la expresión de las necesidades de los grandes grupos ciudadanos; y en consecuencia, no se han dedicado sustantivamente a crear conciencia sobre los principales problemas que debemos resolver para sobrevivir (véase el cuadro 1). 


\section{Cuadro 1 \\ Diagrama de participación de los movimientos sociales en México a través de los medios de comunicación}

\begin{tabular}{|c|c|c|c|c|c|}
\hline \multicolumn{3}{|c|}{ Mayor apertura a la participación social } & \multicolumn{3}{|c|}{ Menor apertura a la participación social } \\
\hline \multicolumn{6}{|c|}{ 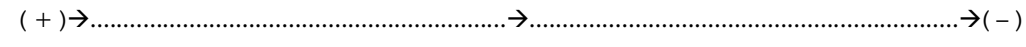 } \\
\hline $\begin{array}{l}\text { Medios } \\
\text { impresos } \rightarrow\end{array}$ & $\begin{array}{l}\text { Nuevas } \\
\text { tecnologías } \\
\text { 'ligeras' } \rightarrow\end{array}$ & Cine $\rightarrow$ & Radio $\rightarrow$ & $\begin{array}{l}\text { Televisión y } \\
\text { video } \rightarrow\end{array}$ & $\begin{array}{l}\text { Nuevas tecnologías } \\
\text { 'pesadas' }\end{array}$ \\
\hline $\begin{array}{l}\text { Prensa, revistas } \\
\text { y folletos }\end{array}$ & $\begin{array}{l}\text { Videocasetes, } \\
\text { computadoras } \\
\text { personales, } \\
\text { discos } \\
\text { compactos, } \\
\text { etcétera }\end{array}$ & & & & $\begin{array}{l}\text { Satélites de } \\
\text { comunicaciones }\end{array}$ \\
\hline
\end{tabular}

Fuente: elaboración propia.

Constatamos, por ejemplo, que las organizaciones campesinas no cuentan con espacios televisivos para que desde éstos soliciten apoyos crediticios para ejercerlos en el campo, exijan mejores precios de garantía a sus cosechas, demanden el reparto de tierras, o denuncien el extendido cacicazgo y la corrupción de autoridades o funcionarios. Los sindicatos tampoco cuentan con tiempo informativo para pedir aumentos salariales, elevar sus condiciones generales de vida, o denunciar las anomalías existentes en su interior.

Los partidos políticos tampoco gozan de suficiente margen televisivo para fortalecer su participación en la sociedad, perfeccionar el sistema electoral, mantener contacto masivo con sus representados, o difundir sus propuestas y posiciones partidistas. No obstante que actualmente vivimos una fase de colapso ambiental en el valle de México y el resto del país por la profunda relación destructiva que mantenemos con la naturaleza, los movimientos ecologistas no cuentan con ningún espacio de las redes nacionales de televisión para difundir su labor en pro de la defensa de la vida.

A pesar de que sobre los sectores magisteriales descansa la formación del capital cerebral del país a través de la acción educativa, éstos tampoco cuentan con espacios en los medios audiovisuales para contrarrestar la acción deformante de la cultura parasitaria que ha creado la sociedad de consumo, y en contrapartida fortalecer el proyecto educativo de la escuela nacional. Las diversas asociaciones religiosas que componen el complejo espectro religioso de nuestro país tampoco tienen acceso a los 
medios de información, salvo los espacios que pagan ellas mismas.

Otras células básicas, como los productores agropecuarios, los transportistas, los grupos de amas de casa, las asociaciones de padres de familia, los grupos de colonos, los estudiantes, los profesionistas, las organizaciones no gubernamentales (ONG), entre otras, tampoco disponen de espacios en las pantallas para plantear y discutir sus problemáticas particulares.

Los numerosos grupos indígenas fundadores desde hace milenios de nuestro territorio y cultura, hoy en día, al iniciar el siglo XXI, no tienen ningún espacio en la televisión para expresar sus necesidades, cosmovisión, pluriculturalidad, originalidad, dolor o tristeza generado desde hace más de 510 años por la conquista española y por la marginación en que los ha colocado el proyecto occidental de desarrollo nacional. La única excepción de este caso es la participación de las etnias en las radiodifusoras indígenas, pero fuertemente mediatizadas por los mecanismos de control oficial a cargo del Instituto Nacional Indigenista (INI), lo cual impide la expresión de los intereses y necesidades de las etnias (véanse los cuadros 2, 3 y 4).

Este control gubernamental de las radiodifusoras indígenas ha impedido que las etnias participen de forma constante y directa en la construcción de un nuevo espacio público que contribuya a crear otra cultura para la sobrevivencia nacional. En cambio, dichos espacios de participación han funcionado más bien como un espacio de control indígena y de legitimación del viejo Estado.

Es por ello que es necesario repensar qué hacer en términos políticos para crear otro proyecto colectivo de comunicación social, que rescate el espíritu democratizador de la sociedad mexicana y permita la expresión de los grandes grupos a través de los medios de difusión colectivos, especialmente de los grupos indígenas. 


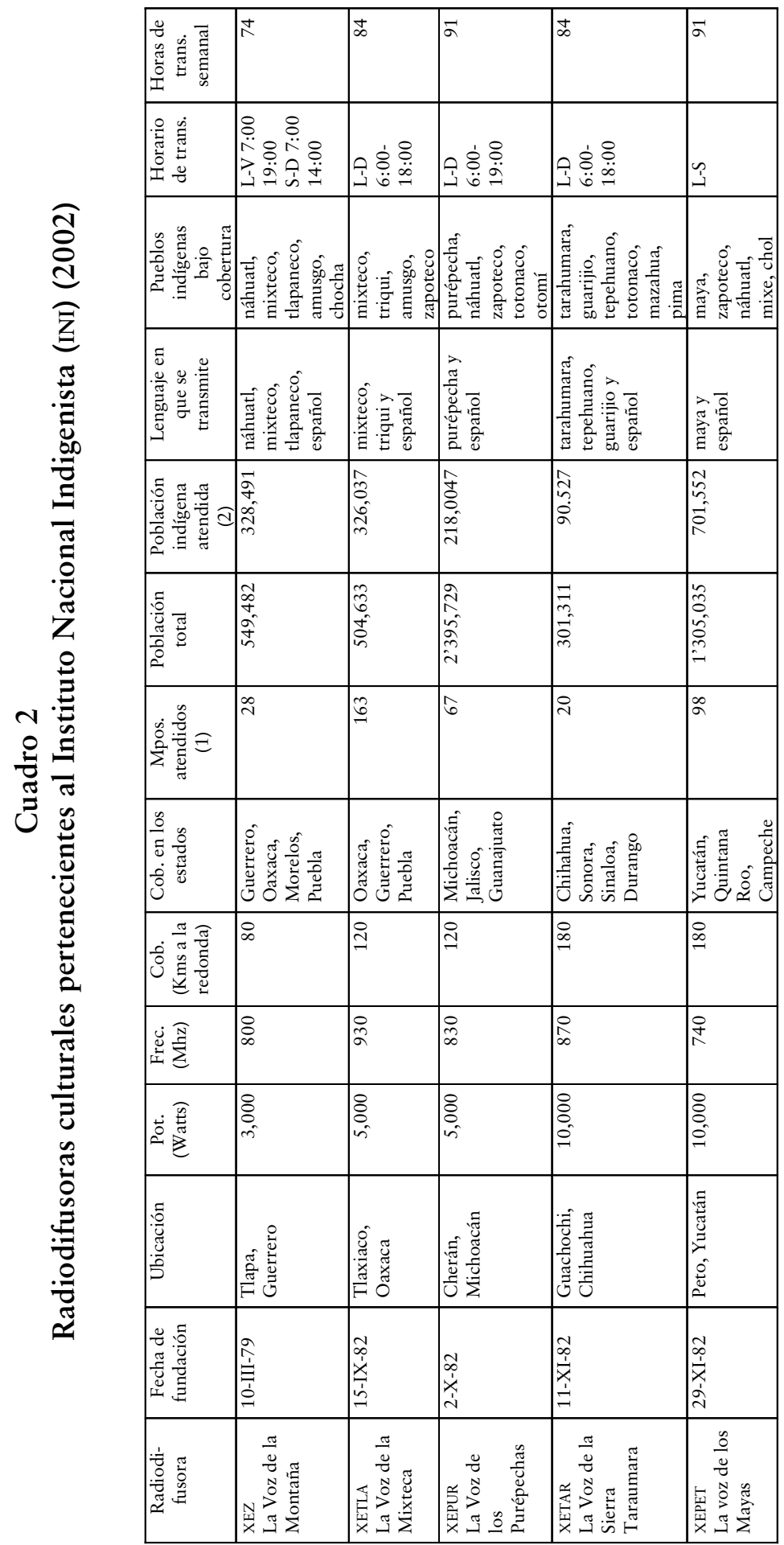




\begin{tabular}{|c|c|c|c|c|c|c|}
\hline 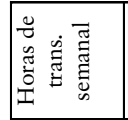 & $\mid \begin{array}{l}n \\
\infty \\
\infty \\
\infty\end{array}$ & $\stackrel{n}{=}$ & $\infty$ & 8 & in & in \\
\hline 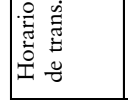 & > & 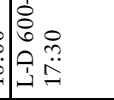 & | & ن & نُ & 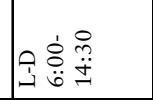 \\
\hline 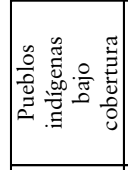 & 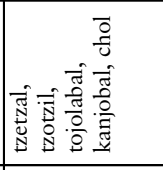 & 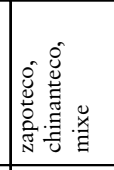 & 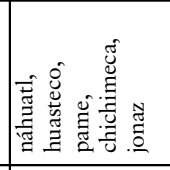 & 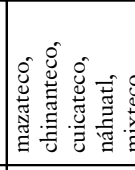 & 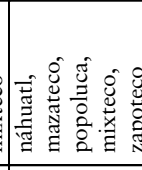 & 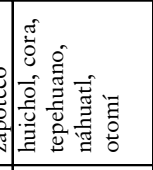 \\
\hline 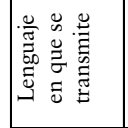 & 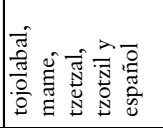 & 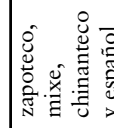 & 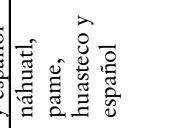 & 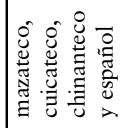 & 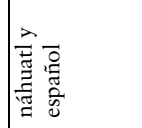 & 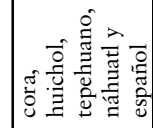 \\
\hline 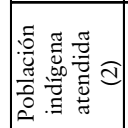 & 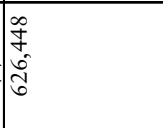 & 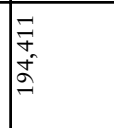 & 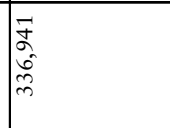 & 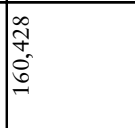 & 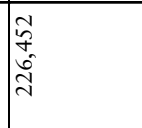 & $\begin{array}{l}\vec{n} \\
\bar{n} \\
2 \\
m \\
m\end{array}$ \\
\hline 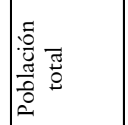 & 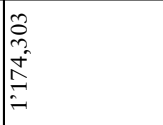 & $\begin{array}{l}\hat{1} \\
\hat{y} \\
0 \\
0 \\
0\end{array}$ & 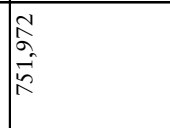 & 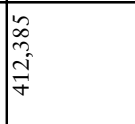 & 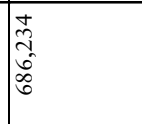 & $\begin{array}{l}\hat{y} \\
\hat{q} \\
\hat{\jmath} \\
\tilde{A}\end{array}$ \\
\hline ن. & $\infty$ & $\infty$ & $\tilde{\lambda}$ & 2 & m & $\wedge$ \\
\hline 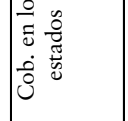 & 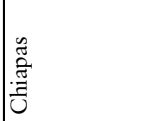 & 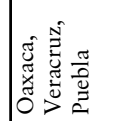 & 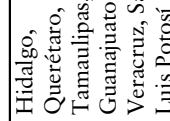 & 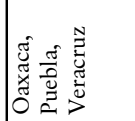 & 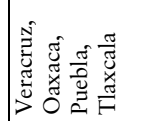 & \\
\hline 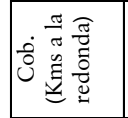 & 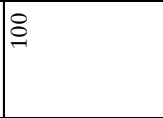 & ปิ & స్ & Iิ & I & ปิ \\
\hline$\dot{\underline{y}}$ & 足 & $\stackrel{\circ}{\circledR}$ & 足 & 品 & 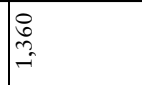 & in \\
\hline 产 & $\begin{array}{l}8 \\
8 \\
+ \\
+\end{array}$ & 离 & is & 竞 & is & 离 \\
\hline 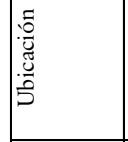 & 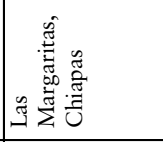 & 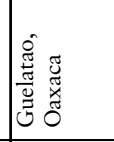 & 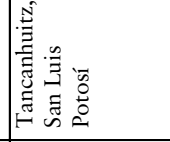 & 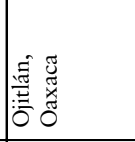 & 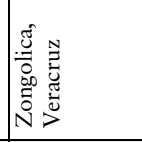 & 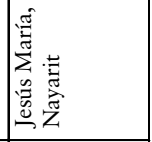 \\
\hline 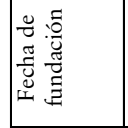 & 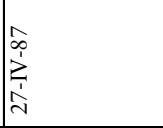 & 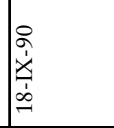 & 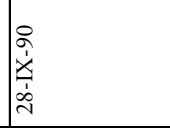 & \begin{tabular}{|l}
$\overline{2}$ \\
章 \\
$\dot{9}$ \\
\end{tabular} & 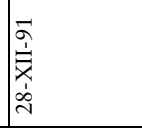 & 年 \\
\hline 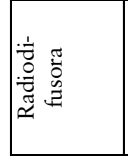 & 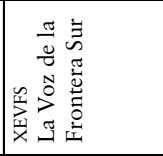 & 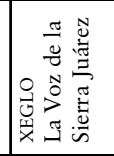 & 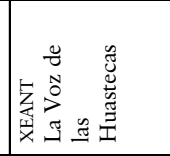 & 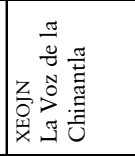 & 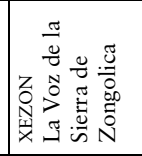 & 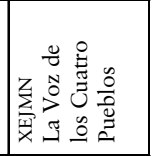 \\
\hline
\end{tabular}




\begin{tabular}{|c|c|c|c|c|c|c|}
\hline 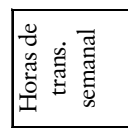 & $\infty$ & $\bar{\sigma}$ & \begin{tabular}{|l|}
$\infty$ \\
$\infty$
\end{tabular} & & in & $R$ \\
\hline 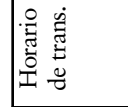 & is & 家 & 定 & 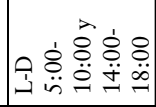 & $\mid$ & 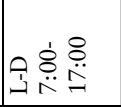 \\
\hline 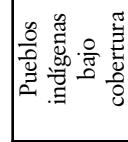 & 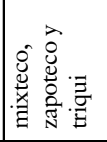 & 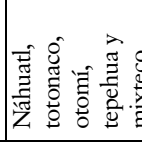 & 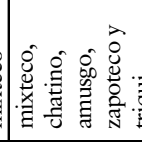 & 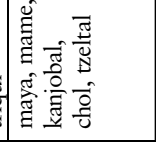 & 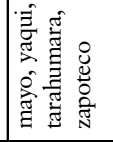 & 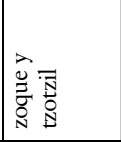 \\
\hline 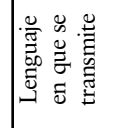 & 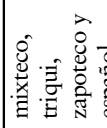 & 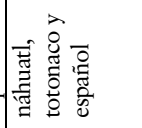 & 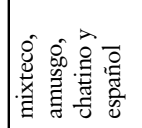 & 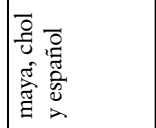 & & 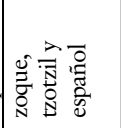 \\
\hline 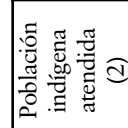 & $\begin{array}{l}\hat{2} \\
\vec{\lambda}\end{array}$ & $\begin{array}{l}\text { ì } \\
\text { in } \\
\text { in }\end{array}$ & 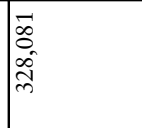 & 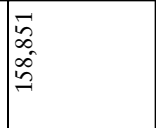 & \begin{tabular}{l} 
a \\
\multirow{a}{*}{} \\
$\vec{a}$
\end{tabular} & $\begin{array}{l}\vec{D} \\
\infty \\
\dot{\mathbb{m}} \\
\dot{m}\end{array}$ \\
\hline 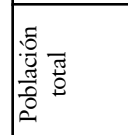 & 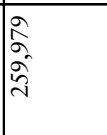 & $\begin{array}{l}\infty \\
0 \\
\cdots \\
0 \\
0\end{array}$ & 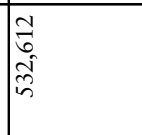 & $\begin{array}{l}0 \\
\infty \\
\infty \\
i \\
i n \\
i n\end{array}$ & $\begin{array}{l}2 \\
2 \\
2 \\
2 \\
2\end{array}$ & $\begin{array}{l}0 \\
0 \\
0 \\
0 \\
1 \\
\infty \\
\infty\end{array}$ \\
\hline 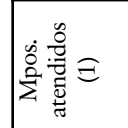 & - & to & त & $\wedge$ & $\infty$ & $\hat{m}$ \\
\hline 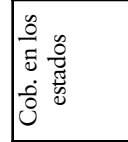 & 离 & 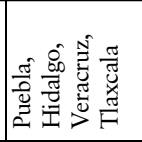 & 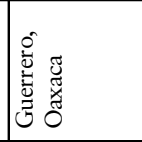 & 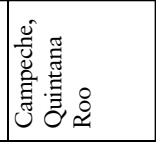 & 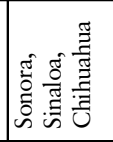 & 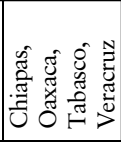 \\
\hline 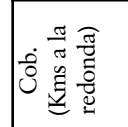 & $R$ & ఫิ & Iิ & ఫิ & 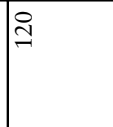 & ปิ \\
\hline 误哥 & 袷 & 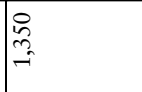 & 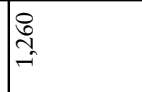 & 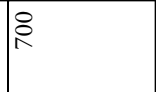 & $\stackrel{0}{\circ}$ & î \\
\hline 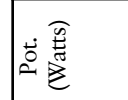 & 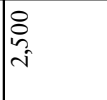 & 离 & 离 & 离 & is & $\underbrace{}_{0}$ \\
\hline : & 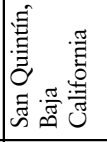 & 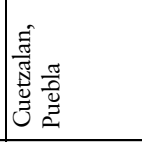 & 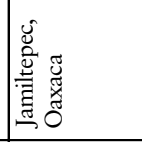 & 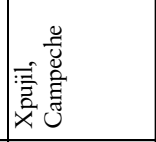 & 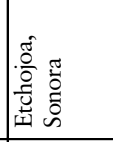 & 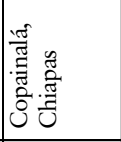 \\
\hline 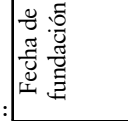 & 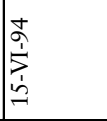 & 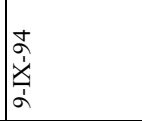 & 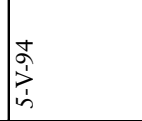 & 永 & 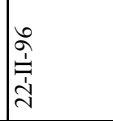 & ha \\
\hline 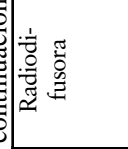 & 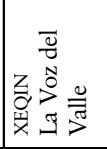 & 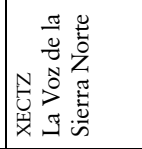 & 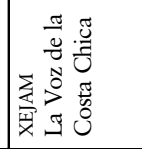 & 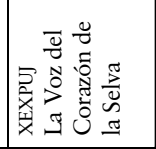 & 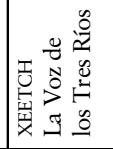 & 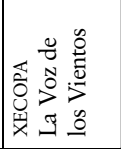 \\
\hline
\end{tabular}




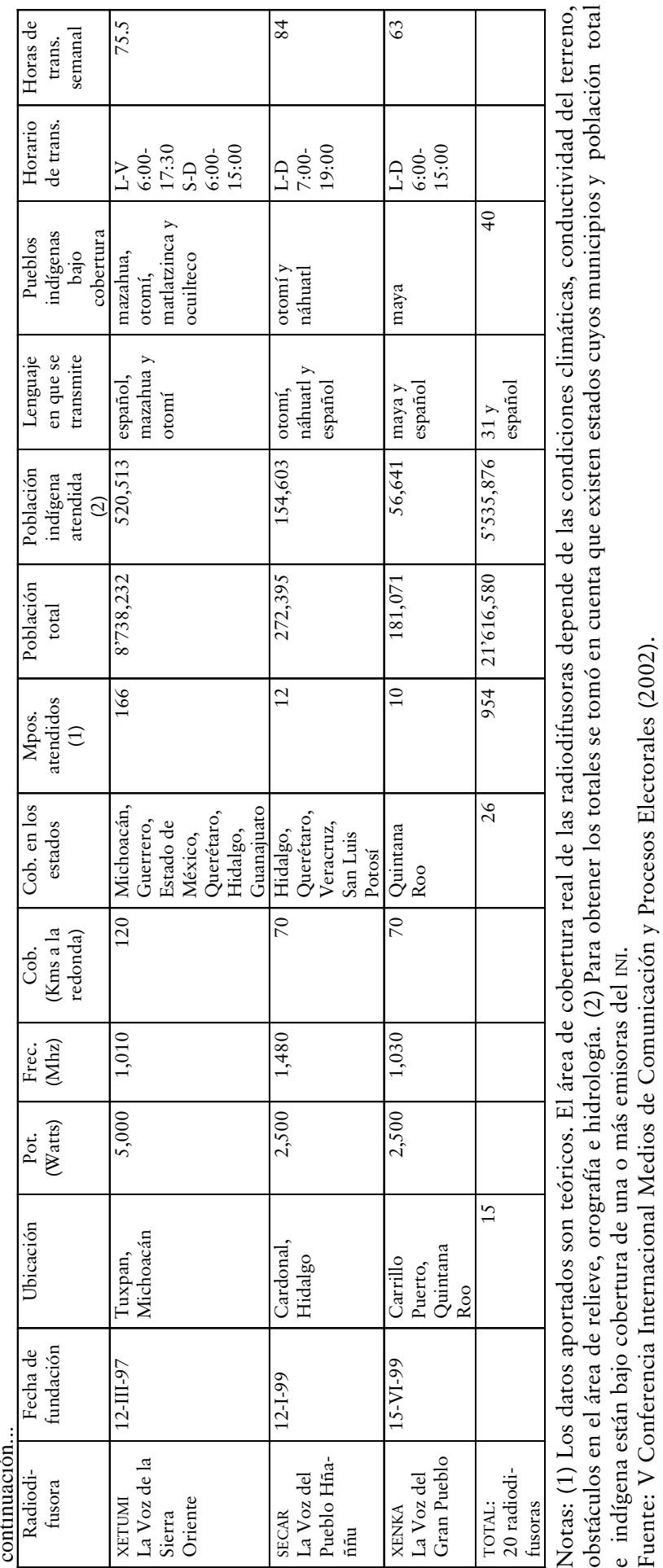




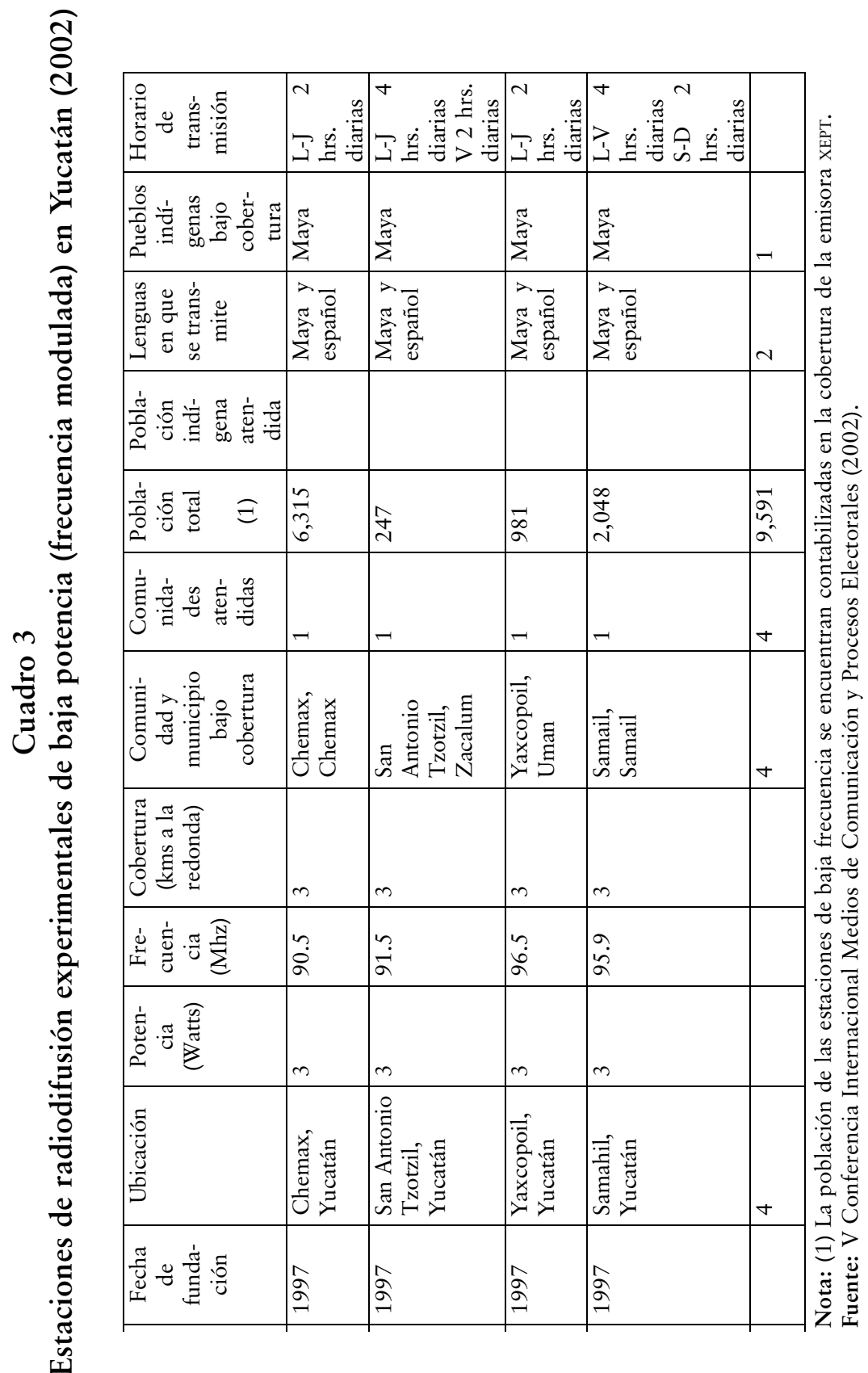




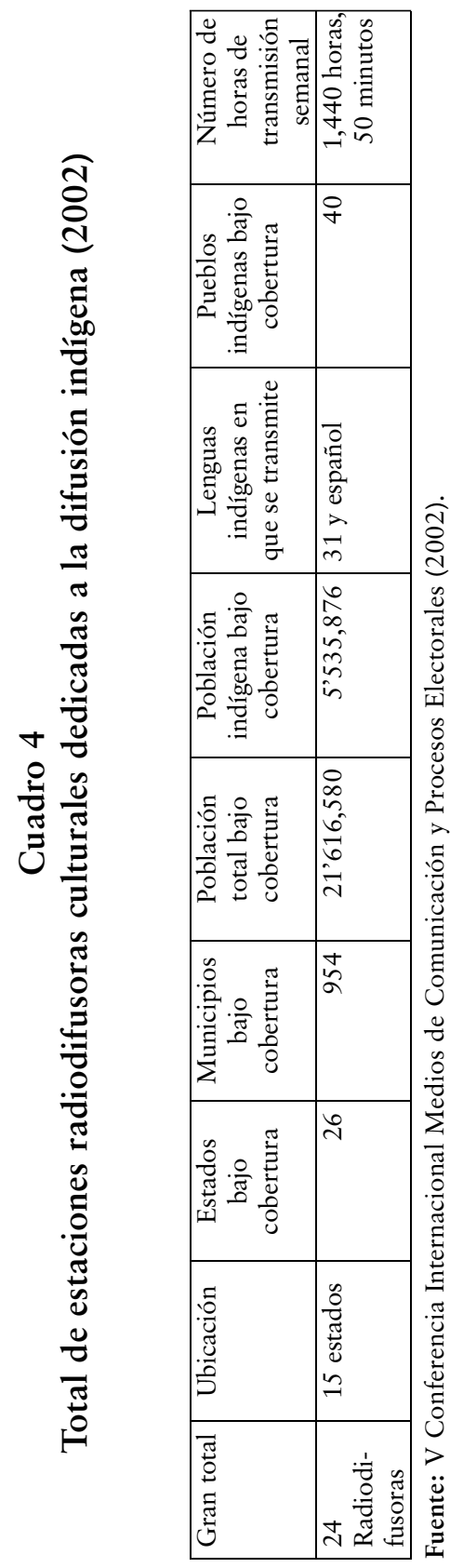




\section{El acceso de los pueblos indios a los medios de comunicación social: acuerdo engañoso}

Hoy decimos iBasta!

Subcomandante Marcos,

Ejército Zapatista de Liberación Nacional

Como forma de respuesta radical a la profunda desigualdad histórica que han sufrido los pueblos indios en México en todos los ámbitos de sus vidas desde hace cinco siglos, el 1 de enero de 1994 se levantó en armas el Ejército Zapatista de Liberación Nacional (EZLN) declarando la guerra al gobierno mexicano y exigiendo la reivindicación urgente de los derechos indígenas. ${ }^{1}$

Frente a la situación de bárbara injusticia histórica sobre las comunidades indígenas, el gobierno mexicano y el EZLN, después de varios años de negociaciones entre sí, firmaron el 16 de febrero de 1996 los Acuerdos de San Andrés Larráinzar, que en esencia plantearon la construcción de otro pacto social, integrador de una nueva relación entre los pueblos indígenas, la sociedad y el Estado. Por otra parte, con el fin de reanudar el diálogo con el EZLn, el 5 de diciembre de 2000 el presidente Vicente Fox envió al H. Congreso de la Unión la nueva Iniciativa de Reforma de Cultura y Derechos Indígenas, y lo propio hizo el 7 de diciembre al Senado de la República (Presidencia de la República, 2000b).

Dentro de este contexto histórico, el espíritu de autonomía y dignidad del México profundo (Bonfil, 1988) expresado a través del movimiento insurgente del EZLN planteó como horizonte a lo largo de 7 años que las comunidades autóctonas ven "con esperanza la palabra que se ha alzado de los diferentes pueblos indígenas y que grita un iYA BASTA! Los pueblos indígenas de México hemos abierto un camino hacía la paz, la justicia, la dignidad, la verdad; ahora sólo nos queda mantener nuestro paso firme y unirnos más como comunidad para lograr nuestra meta: MÁs MEDIOS DE COMUNICACIÓN EN FAVOR DEL PUEBLO" (Acción Social de los Jesuitas en México, 1996).

Es por ello que, en síntesis, en materia de cultura y acceso a los canales de información, los Acuerdos de San Andrés Larráin-

\footnotetext{
${ }^{1}$ La grave problemática en México ha sido analizada por importantes especialistas durante varios años, dentro de los cuales destacan Aguirre Beltrán (1983), Stavenhagen (2001), Stavenhagen e Iturralde (1990), Bodley (1982), Florescano (2001), Díaz Polaco (1991), Kohn (1992), Bonfil (1988), Sandoval y Patiño (2000), Smith (1993), Giménez (2000), entre otros. En este ensayo no repetiremos los valiosos planteamientos expuestos por dichos estudiosos, ya que nuestro objetivo concreto es el examen de la participación de los pueblos de indios en el proceso de construcción de la nación a través de los medios de comunicación.
} 
zar y la Iniciativa de Ley de Reforma de Cultura y Derechos Indígenas formularon en esencia en los puntos 9 y 7 respectivamente, que el Estado mexicano reconoce que "los pueblos indígenas tienen el derecho a la libre determinación y a la autonomía, como parte del Estado mexicano [...] para adquirir, operar y administrar sus propios medios de comunicación" (Gobierno de México, 2001: 91-93 y Presidencia de la República, 2000a).

Este acuerdo se reforzó políticamente cuando Xóchitl Gálvez Ruiz, Jefa de la Oficina para el Desarrollo de los Pueblos Indígenas, le planteó al presidente Vicente Fox Quesada:

las comunidades indígenas necesitamos tener más espacios en los medios de comunicación para informar a nuestra gente, para desaparecer ese temor que existe en nuestros pueblos (Gálvez, 2001a).

Ante esta demanda, el presidente Fox se comprometió públicamente en la televisión regional de Chiapas a

hablar con el Secretario de Comunicaciones y Transportes y con el Secretario de Gobernación para ver esa posibilidad. Yo no veo que haya mucho problema de que nos extendamos en tener más participación de radiodifusoras para las comunidades indígenas, y lo mismo en televisión. Eso se puede hacer y me parece muy interesante y vamos a apoyarla (Gálvez, 2001a).

Con estos elementos jurídico-políticos quedaron asentadas las bases de negociación del pacto social existente entre pueblos indios, Estado y el acceso a los medios de comunicación entre el EZLN y el Congreso. A pesar de haber transcurrido muchos años de presión y negociación, es asombroso lo limitado y engañoso de este acuerdo consensuado entre gobierno y EZLN por las siguientes cinco razones:

1. El reconocimiento del Estado mexicano de que los pueblos indígenas tienen el derecho a la libre determinación y a la autonomía para adquirir, operar y administrar sus propios medios de comunicación no implica ningún nuevo avance en la lucha de las comunidades autóctonas para contar con medios de expresión propios, pues son derechos abstractos básicos que la Constitución Política de los Estados Unidos Mexicanos y la Ley Federal de Radio y Televisión ya reconoce a todos los ciudadanos mexicanos con mucha anterioridad al surgimiento del movimiento zapatista, el 1 de enero de 1994. Así, en primer término, el Artículo $6^{\circ}$ de la Constitución mexicana señala que

la manifestación de las ideas no será objeto de ninguna inquisición judicial o administrativa, sino en el caso de que ataque a la moral, los derechos de terceros, provoque algún delito, o perturbe el orden público; el 
derecho a la información será garantizado por el Estado (Constitución Política de los Estados Unidos Mexicanos, 2001: 6-7).

\section{El artículo 7 de la Constitución consagra que}

es inviolable la libertad de escribir y publicar escritos sobre cualquiera materia. Ninguna ley ni autoridad puede establecer la previa censura, ni exigir fianza a los autores o impresores, ni coartar la libertad de imprenta, que no tiene más límites que el respeto a la vida privada, a la moral y a la paz pública... (Constitución Política de los Estados Unidos Mexicanos, 2001: 6-7).

En segundo término, la Ley Federal de Radio y Televisión acepta en el Artículo 58 que

el derecho de información, de expresión, y de recepción, mediante la radio y la televisión, es libre y consecuentemente no será objeto de ninguna inquisición judicial o administrativa ni de limitación alguna ni censura previa, y se ejercerá en los términos de la Constitución y de las leyes (Ley Federal de Radio y Televisión y su Reglamento, 2000: 28).

En tercer término, el artículo 30 del Convenio 169 de la Organización Internacional del Trabajo (OIT) sobre Pueblos Indígenas y Tribales, firmado por el Senado de la República de México en 1989, señala en sus incisos 2 y 3 lo siguiente:

los gobiernos deberán adoptar medidas acordes a las tradiciones y culturas de los pueblos interesados, a fin de darles a conocer sus derechos y obligaciones, especialmente en lo que atañe al trabajo, a las posibilidades económicas, a las cuestiones de educación y salud, a los servicios sociales y a los derechos dimanantes del presente Convenio. Para tal fin, deberá recurrirse, si fuere necesario, a traducciones escritas y a la utilización de los medios de comunicación de masas en las lenguas de dichos pueblos (orT, 1997: 10).

Por este motivo, dicho acuerdo sólo repite un derecho que ya es propio de cualquier mexicano y no agrega ninguna garantía, derecho, facultad o mecanismo nuevo para que los pueblos indios puedan tener sus propios medios de comunicación colectivos, por consiguiente todo sigue igual.

2. En caso de que se amplíe políticamente la propuesta y se apruebe la existencia autónoma de medios de comunicación indígenas, la iniciativa introduciría una grave contradicción de carácter técnico-jurídico, pues el planteamiento establecería un régimen normativo de excepción para los pueblos indios, al aceptar la autorregulación total de éstos, que entraría en oposición con el conjunto de otras leyes, al proponer que éstos gocen de un derecho extraconstitucional, por encima del régimen actual de concesiones y permisos que formula la Ley Federal de Radio y Tele- 
visión, al que deben de sujetarse obligatoriamente el resto de los mexicanos (Warman, 2001: 16-17 y Noticiario Cúpula Empresarial s.f.).

En consecuencia, la actual formulación de este punto "deja en la incertidumbre tanto la dotación como la promulgación de una nueva ley que dote a los pueblos indios de medios de comunicación y garantice su uso y operación, como estaba establecido en los Acuerdos de San Andrés. La propuesta de la Comisión de Concordia y Pacificación (Cocopa) tampoco dice nada en concreto para lograr que los pueblos indios tengan sus propios medios de comunicación" (FZLN, 1998: 5). Por lo tanto, la propuesta es contradictoria e inviable, a menos que se modifique la actual Ley de Radio y Televisión, lo cual implica una transformación constitucional de mayor profundidad que rebasaría el marco actual de la negociación indígena.

3. La actual propuesta reduce su planteamiento a un derecho ya obtenido por los mexicanos y desconoce todos los elementos restantes que ha planteado el movimiento zapatista a lo largo de ocho años para progresar en la creación de un nuevo pacto profundo de relación comunicativa entre Estado, comunidades indígenas y sociedad global. De esta forma, el acuerdo desconoce elementos como la elaboración de una nueva ley de comunicación social que incluya los derechos de los ciudadanos, el reconocimiento del derecho a la comunicación, la reglamentación del derecho a la información, la creación del derecho de réplica, la eliminación de los monopolios informativos, la no privatización de los espacios públicos, la creación de la figura del Ombudsman de la comunicación, el uso de 12.5\% del tiempo oficial para la participación de los grupos indios, la modificación de la política de otorgamiento de concesiones de radio y televisión, el fortalecimiento del modelo de medios de servicio público, el fin de la relación de contubernio existente entre medios y Estado, la reducción del comercialismo en los medios, la tipificación como delito a la manipulación y la desinformación de la opinión pública, la supresión de las expresiones sexistas y racistas del lenguaje, mayor autonomía de participación de las comunidades indígenas en las radiodifusoras indígenas, etcétera.

4. La iniciativa de ley tampoco considera un mecanismo financiero elemental para que los pueblos indios puedan adquirir sus propios medios de comunicación o la compra de espacios de expresión dentro de éstos, sino que deja el ejercicio de ese derecho a la capacidad económica de las comunidades indias. Esto 
significa que dicha garantía constitucional será casi imposible de aplicar a los sectores indígenas, pues la casi totalidad de las comunidades autóctonas viven en la miseria, la marginación y el hambre, sin contar con recursos para destinarlos a este fin, que exige grandes inversiones económicas.

5 . Finalmente, la propuesta tampoco incluye procedimiento concreto u operativo alguno para permitir la integración de los indígenas dentro de la actual estructura de canales de información nacionales. Continúa dejando fuera o en el vacío a la participación de los pueblos indios en los medios de comunicación.

Al parecer, a principios del siglo XXI y del nuevo gobierno de transición democrática, en el terreno de la comunicación se sigue sin contar con la suficiente voluntad política por parte del Poder Ejecutivo para encontrarle la cuadratura al círculo y permitir que la sociedad mexicana cuente con los derechos universales básicos en materia de información.

Lo más asombroso de esta situación es que la casi totalidad de la opinión publica nacional, incluyendo a la inteligencia y al periodismo críticos, centró su atención en los aspectos frívolos y secundarios del proceso y la marcha zapatista y no en la discusión o enriquecimiento profundo de las propuestas presidenciales enviadas al Congreso de la Unión para ser negociadas con el EZLN en materia de comunicación social. Así, la atención giró alrededor de si los zapatistas vienen a negociar con máscara o sin máscara; cómo se comportó Marcos en la entrevista con el comediante Ponchito; el estreno del presidente Fox como conductor radiofónico en el programa Fox en Vivo, Fox Contigo para entrevistar a los representantes indígenas (Presidencia de la República, 2001); las características que tuvo el Concierto por la Paz o Chiapatón que organizaron Televisa y Televisión Azteca; los comerciales televisivos que la empresa Viana realizó para vender productos electrodomésticos con imágenes de Marcos, el Comandante Tacho y el EzLN; ${ }^{2}$ y no en el análisis del punto 9 de los Acuerdos de San Andrés o del punto 7 de la Iniciativa de Ley de Reforma de Cultura y Derechos Indígenas para la reivindicación histórica de los indígenas.

Algo sumamente grave y profundo sucedió en la conciencia nacional, pues ante un hecho histórico trascendente en mate-

\footnotetext{
${ }^{2}$ Durante varias semanas de principios del año 2001, la empresa Viana aprovechó diversas imágenes actuadas del EZLN para elaborar spots publicitarios que promovían sus mercancías, especialmente del ramo de electrodomésticos. Para ampliar este punto véase Vértiz (2001b: 82).
} 
ria de derecho a la información (quizás el más importante en los últimos treinta años), ni el periodismo crítico, ni los partidos políticos, ni las organizaciones no gubernamentales, ni las escuelas de comunicación, entre otros actores, asimilaron dicha situación desde un ángulo crítico o analítico, y también quedaron hipnotizados por el gran glamour y poder mediático regenerador de los medios de difusión que creó un ambiente de paz virtual en technicolor. Cuando más, sólo algunos analistas políticos criticaron tangencialmente la realización del Concierto por la Paz (Vértiz, 2001a: 86-87 y Toussaint, 2001a:83-84) o la entrevista concedida por el presidente Fox a Ponchivisión; la difusión espectacular de la Caravana de la Dignidad (Toussaint, 2001b: 84 y Solórzano, 2001: 26) o la manipulación de algunas imágenes de la marcha zapatista, pero no reflexionaron sobre lo fundamental: ¿Cómo lograr que las comunidades indígenas accedan a los medios de información colectivos para transmitir su otra versión de la vida y de la historia?

Con la realización del Concierto por la paz y la manipulación de algunas transmisiones televisivas por parte de Televisa y Televisión Azteca, se creó en la opinión pública nacional un clima de presión social para que el zapatismo quedara políticamente acorralado para firmar los Acuerdos de San Andrés tal y como están, sin poder negociar nuevas condiciones favorables para los indígenas. La estrategia informativa de los monopolios de la comunicación prepararon a la opinión pública para acusar de intolerante, infantil, caprichoso, payaso, narcisista, etcétera, al Subcomandante Marcos y al EZLN, en caso de no aceptar las condiciones de la paz.

Así, podemos decir que gradualmente el poder mediático de los medios de información se apoderó de la fuerza simbólica del EZLN, lo convirtió en espectáculo, lo descontextualizó, lo canalizó hacia sus intereses, hipnotizó una vez más a la sociedad y abortó la reflexión y discusión sobre el acceso de los pueblos indios a los medios de comunicación. En una idea: convirtió al movimiento indígena insurgente del EZLN en una mercancía informativa más del consumo cultural masivo posmoderno, que fue desechada cuando ya no registró raiting y fue cambiada por otros hechos coyunturales mercadológicamente más rentables.

Esta realidad es una prueba más de cómo la cultura idiota, a partir de la agenda setting que generan los medios de comunicación, nos ha hecho olvidar lo principal, con el fin de que nuestra conciencia gire alrededor de lo secundario, lo anecdótico, lo frívolo, lo descontextualizado o lo terciario. Es la reproducción 
ampliada del alzhaimer cultural en el ámbito nacional y el avance de la cultura light en los medios de información social.

Con el apoderamiento del mito y la simbología del EZLN por parte de los medios de información colectivos, el movimiento libertario del EZLN pasó en unas semanas de ser noticia para convertirse en una mercancía más del consumo cultural de masas.

Toda esta asombrosa realidad contradictoria en México muestra, por una parte, que la cultura colectiva generada por los medios de información seguirá siendo unidimensional y occidentalizada, y no multi y pluricultural, pues los 62 pueblos indígenas, con sus 62 lenguas diferentes y sus 30 variantes (en total 92 lenguas distintas) (Gálvez, 2001a), seguirán sin participar o aportar su cosmovisión dentro del espectro de la cultura de masas. Con ello, el modelo de comunicación-mercado que hoy domina en la comunicación colectiva continuará fortaleciendo los parámetros de la cultura idiota que tanto ha erosionado mental y espiritualmente a nuestro país y no al modelo de servicio público que le urge a nuestro horizonte cultural nacional para sobrevivir. Por otra parte, muestra que el resto de los acuerdos logrados por el EZLN frente al Estado federal en materia de autonomía, derechos humanos, sustentabilidad, libre determinación, plurietnicidad, autogobierno, especificidades culturales, participación y representación política, protección a migrantes étnicos, formas de organización, uso y disfrute de los recursos naturales, preservación de sus lenguas, impulso a sus culturas, satisfacción de necesidades básicas, entre otras demandas de los pueblos indígenas se encuentran en condiciones muy frágiles de consolidación, pues para garantizarlos, a mediano y largo plazos, se requiere contar con una sólida base de poder para defenderlos. Hoy en día, al inicio del siglo xxI en México, el acceso al primer poder se deriva del acceso a los medios de comunicación colectivos. Si no se cuenta con acceso a la estructura de información, difícilmente se pueden defender otras conquista sociales ya obtenidas.

Por esta razón, en cuanto a la realización del derecho a la información de los indígenas, ahora resulta indispensable y urgente que el EZLN y la sociedad civil abran los ojos y elaboren nuevas propuestas políticas, jurídicas, económicas y culturales, a nivel conceptual y operativo, para pactar e implantar, de manera real y no retórica, los acuerdos de San Andrés Larráinzar y la nueva Iniciativa de Ley Sobre Cultura y Derechos Indígenas en México. En este sentido, es fundamental retomar el espíritu de 
dignidad y autonomía planteado por las comunidades autóctonas en el III Congreso Nacional Indígena, que en cuanto al acceso indio en los medios de difusión planteó

la apropiación y acceso Constitucional de los Pueblos Indios a los medios de comunicación [...] para difundir nuestra cultura, tradiciones y hacer escuchar nuestra palabra... (III Congreso Nacional Indígena, 2001: 4-9).

En consecuencia, en materia de comunicación colectiva es necesario romper la cuadratura del círculo que tradicionalmente ha argumentado el gobierno federal para evitar democratizar el sistema de comunicación nacional. De lo contrario, en el campo de la comunicación social de muy poco habrá servido el levantamiento armado, el monumental sacrificio indio y el derramamiento de sangre que el EZLN ha realizado durante nueve años, pues todo continuará igual: contrariamente al lema del levantamiento zapatista: iNunca más un México sin nosotros!, los indígenas seguirán sin voz y el proyecto planetario de globalización mundial continuará creando un México posmoderno, sin la presencia de los indígenas.

\section{Propuesta: reforma del Estado mexicano, transformación del pacto social y participación indígena en los medios de comunicación}

Hacia una reforma agraria del aire

Diálogo de Sacam Ch'en de los Pobres

Para ciudadanizar los medios de información en México y crear algunas formas de participación de los grandes grupos sociales en éstos, especialmente de los indígenas, es indispensable modificar de el viejo y desequilibrado pacto social existente entre el Estado mexicano, los medios de comunicación y la sociedad, que sirvió de base para consolidar durante setenta años al decadente régimen político anterior. Ahora es necesario construir, mediante la reforma del Estado, una nueva relación democrática, plural, equilibrada y abierta que permita que los ciudadanos participen colectivamente a través de los medios de comunicación, para contribuir en la construcción y el enriquecimiento del espectro político-cultural de nuestra nación y crear una nueva cultura civilizatoria superior que nos permita sobrevivir en nuestro país.

Debemos reconocer que "la reforma del Estado en materia de comunicación, no es una reforma jurídica más para modernizar al Estado mexicano; sino que por su naturaleza vertebral que 
cruza todos los ámbitos de la vida comunitaria y cotidiana, es la reforma más importante de la sociedad mexicana de principios del siglo XXI, pues será a partir de esta renovación como se determinarán las vías que modificarán o no los procesos para construir la conciencia colectiva nacional de final de milenio. De ello dependerá si se crean las bases político-sociales para generar una conciencia para el avance de la República o para su retroceso mental, social y civilizatorio en el nuevo milenio" (Esteinou, 2002).

La transformación de la estructura de comunicación nacional es un proceso muy complejo que requiere la participación no sólo del Estado, sino de muchos otros sectores de la sociedad en diversos planos de acción. Por ello, para avanzar en la reforma del Estado mexicano en materia de comunicación y construir una nueva politica nacional de comunicación, particularmente para la participación de los pueblos indios, se deberán contemplar y realizar, entre otras, las siguientes acciones de transformación de la estructura informativa en el plano político, legislativo, civil y académico.

\subsection{En el plano político}

1. El Estado debe rescatar su función rectora en el campo de la comunicación frente a la dinámica salvaje que han alcanzado las fuerzas del mercado en este terreno, para construir un nuevo proyecto de comunicación nacional basado en la participación de la sociedad, especialmente de las comunidades indígenas, que han sido históricamente marginadas de los medios de comunicación.

Para ello es necesario que se replanteen las bases del pacto social de comunicación entre el Estado, los medios de información y la sociedad civil, con el fin de orientarlo hacia un nuevo acuerdo tripartita de participación colectiva, con incidencia privilegiada de la sociedad civil y que equilibre el actual funcionamiento desigual entre estos sectores. En la conformación de este nuevo pacto social debe ocupar un lugar destacado la presencia de los grupos indígenas.

2. Para avanzar en la consolidación de este nuevo pacto comunicativo, es imperativo que el Estado fortalezca y amplíe el esquema de medios de comunicación de servicio público, a través de las siguientes dos vías: 
i. El aumento directo de financiamiento por parte del Estado a sus medios públicos para ampliar su infraestructura técnica, material, informativa y salarial. Dentro de esta nueva recapitalización, deberán tener preferencia el apoyo a los proyectos de participación comunicativa de la sociedad civil, preferencialmente de las etnias indígenas.

ii. El uso intensivo de $12.5 \%$ del tiempo oficial que legalmente ya le corresponde al Estado mexicano en los espacios de programación de los medios privados. Para alcanzar esto, se propone aprovechar una porción de dicho tiempo en todos los medios comerciales privados, para formar una amplia franja de información de Estado de servicio público que permita la participación de los sectores sociales, especialmente grupos indígenas organizados. Esto significaría contar dentro de la propia estructura de los medios comerciales privados con un gran frente de medios de servicio público, con alta penetración y un mínimo de inversión del Estado y de la sociedad.

3. Con el fin de ejercer su función de rector nacional y equilibrar el funcionamiento del modelo desigual de comunicación de mercado que tantas alteraciones mentales ha producido en la cultura nacional, se requiere terminar con la distribución discrecional de los tiempos oficiales, legales, fiscales y electorales del Estado en radio y televisión, y exigir su uso transparente y equitativo que permita, a través de éstos, la participación de los principales grupos sociales, particularmente indígenas (III Conferencia Internacional de Medios de Comunicación y Procesos Electorales, 2000: 300). Para ello, se proponen, entre otros, los siguientes mecanismos:

i. Que la Comisión de Radio, Televisión y Cinematografía (RTC) de la Cámara de Diputados y de la Cámara de Senadores de la XLVIII Legislatura, junto con representantes de la sociedad civil organizada, incluyendo privilegiadamente a los indígenas, vigilen sistemática y rigurosamente el otorgamiento de dichos espacios.

ii. Que el actual Consejo Nacional de Radio y Televisión, reconocido por el Artículo 90 de la Ley Federal de Radio y Televisión y que tiene la responsabilidad de "elevar el nivel moral, cultural, artístico y social de las transmisiones" (Ley Federal de Radio y Televisión y su Reglamento, 2000: 3637), añada entre sus miembros a dos representantes de los 
grupos indígenas de la República, dos representantes del sector académico y dos representantes de la sociedad civil organizada, para supervisar, con base en la legislación existente, el correcto funcionamiento de los medios de información en México.

4. El Estado debe abrir la participación de la sociedad civil organizada, particularmente indígenas, en los tiempos oficiales, ya que son espacios nacionales que se otorgan en las concesiones que la sociedad en su conjunto le delega al Estado para que éste los administre con base en el bien común. En este sentido, es muy importante puntualizar que en la medida en que los grupos y organizaciones sociales cuenten con tiempos en los medios de comunicación electrónicos, se evitará la presencia de tantas manifestaciones callejeras que todos los días suceden en las principales ciudades del país, generando considerables pérdidas económicas, cierre provisional de empresas y comercios, destrucción de bienes, caos vial, ingobernabilidad, anarquía urbana, irritación ciudadana, aumento del stress y pérdida de la calidad de vida de la población. La sociedad toma permanentemente las calles del país por no tener espacios de expresión en los medios de difusión colectivos.

Para ello, se propone destinar en todos los medios de servicio público del Estado (Canal 22, Canal 11, Instituto Mexicano de la Radio, Radio Educación, Sistemas Estatales de Radio y Televisión, radiodifusoras universitarias, etcétera) un espacio cotidiano de programación radiofónica y televisiva plural donde los grupos indígenas del país difundan sus intereses, necesidades y aportaciones culturales. Con esto se podrá rescatar y preservar la cultura y la memoria histórica de los pueblos indígenas de nuestra nación como parte del derecho a la información consagrado en la Constitución mexicana.

5. De manera específica, para incrementar la participación local de los pueblos indios a través de los medios de comunicación, el Estado deberá seguir las siguientes estrategias:

i. Siendo que actualmente en el país existe una población de más de diez millones de indígenas, "con 62 tipos étnicos diferentes y con 62 lenguas diferentes con 30 variantes (estamos hablando de 92 lenguas diferentes)" (Gálvez, 2001a: 2), se deberá aumentar significativamente la existencia del 
número de radiodifusoras indígenas dependientes del Instituto Nacional Indigenista (INI, 2000).

ii. Apoyar sustancialmente en todos los niveles a las radiodifusoras indígenas ya existentes, para que puedan consolidar sus proyectos de apoyo al desarrollo de las comunidades campesinas e indígenas.

iii. Otorgar mayor autonomía a las radiodifusoras indígenas para que se vinculen más libremente con sus comunidades y representen con mayor fidelidad la dinámica de sus vidas y no sólo los intereses de la política centralista del poder federal.

iv. Apoyar la consolidación de las escuelas radiofónicas reconocidas en el capítulo vi de la Ley Federal de Radio y Televisión, para que contribuyan al desarrollo de los grupos indígenas.

6. Es necesario promover la creación de órganos plurales con participación de la sociedad civil en la vigilancia de la normatividad relacionada con el funcionamiento global de los medios de comunicación (Asociación Mexicana del Derecho a la Información, 2000). En la integración de todos estos órganos democráticos deben estar presentes los representantes de los grupos indígenas. Con ello se contribuirá a rescatar y ampliar los pocos espacios que se han dedicado a la difusión y construcción de valores plurales y cívicos a través de los medios de comunicación de masas, y proponer alternativas para impulsar la edificación de una cultura cívico-democrática más madura en nuestro país.

Para ello se propone que en todos los medios de servicio público del Estado se formen consejos consultivos, cuya función sea contribuir a definir la programación y a supervisar el funcionamiento de los mismos. Dichos consejos deben estar integrados por destacados miembros de la sociedad civil, dentro de los cuales deberán existir por lo menos dos representantes de los grupos indígenas del país.

\subsection{En el plano legislativo}

1. Es imperativo elevar a rango constitucional el acceso a la información y a la comunicación como un bien y un derecho público al cual han de acceder todos los mexicanos, particularmente los grupos indígenas. 
2. Es indispensable que se actualice el contexto jurídico amplio de las leyes sobre comunicación social para adaptarla a los desafíos de la sociedad nacional del siglo Xxi. Para ello es muy conveniente que el actual Congreso de la Unión retome el espíritu del proyecto de Ley Federal de Comunicación Social y el Proyecto de Ley Reglamentaria de los Artículos 6 y 7 Constitucionales en materia de Libertad de Expresión y Derecho a la Información preparado por la Comisión de Radio, Televisión y Cinematografía (RTC) de la XLVII Legislatura del Congreso, para discutirlo, perfeccionarlo y proponer una nueva iniciativa de ley de comunicación social.

En este proyecto deberá existir un apartado especial que garantice la participación de los pueblos indios con todos sus derechos en los medios de comunicación.

3. Es indispensable que se discuta en el Congreso de la Unión los criterios de renovación y evaluación de las concesiones de radio próximas a vencer, para proponer el otorgamiento de una de ellas a los diversos grupos indígenas organizados que existen en el país.

Hay que recordar que las concesiones de televisión que están próximas a vencer son las que se muestran en el cuadro 5 .

\section{Cuadro 5}

Vencimiento de concesiones de televisión en el Distrito Federal

\begin{tabular}{|c|l|l|}
\hline Canal & \multicolumn{1}{|c|}{ Adscripción } & \multicolumn{1}{|c|}{ Fecha de vencimiento } \\
\hline 2 & Televisa & 2 de julio de 2009 \\
\hline 4 & Televisa & 1 de septiembre de 2000 \\
\hline 5 & Televisa & 20 de enero de 2009 \\
\hline 7 & TV Azteca & 29 de abril de 2006 \\
\hline 9 & Televisa & 1 de julio de 2009 \\
\hline 13 & TV Azteca & 9 de mayo de 2008 \\
\hline 22 & CONACULTA & 16 de abril de 2001 \\
\hline 40 & Televisora del Valle de México & $2008^{*}$ \\
\hline
\end{tabular}

*No se obtuvo información precisa.

Fuente: Periódico Milenio Semanal, núm. 152, México, 7 de agosto de 2000. Sitio Internet: <http:/www.milenio.com/frame.asp?url>

4. Se necesita garantizar el derecho de réplica en todos los medios de comunicación como una garantía constitucional elemental (Asociación Mexicana del Derecho a la Información, 2000: 56), especialmente de las comunidades indígenas que no cuentan con ningún medio propio para expresarse. Para ello se debe do- 
tar a las comunidades indígenas de espacios de participación periódica en los canales de difusión.

5. Es necesario crear una legislación específica sobre radiodifusoras y televisiones comunitarias de tal manera que permita la participación directa de los indígenas. La legislación sobre radiodifusoras comunitarias debe contemplar, por lo menos, las siguientes características:

i. Debe crearse la figura jurídica de radio comunitaria por una ley federal, de manera separada de la Ley Federal de Radio y Televisión, debido a razones de viabilidad legislativa. En caso de que ello no sea posible, habrá de incorporarse la figura de radiodifusoras comunitaria en este último ordenamiento legal.

ii. Dicha ley debe crearse bajo la figura de permiso, dotado de características especiales, de tal suerte que asegure un servicio social irrestricto que propicie en su función el desarrollo de toda la sociedad.

iii. El permiso debe ser otorgado por la Secretaría de Comunicaciones y Transportes, por acuerdo del Consejo Nacional para la Radio Comunitaria, que funcionará con el fin de garantizar imparcialidad, neutralidad y eficiencia en los procesos de asignación de frecuencias. Este consejo deberá estar compuesto en forma tripartita por representantes de las organizaciones sociales y civiles dedicadas fundamentalmente al ámbito de la comunicación y los derechos humanos, por organizaciones académicas, y por la Secretaría de Educación Pública, como representante de la parte gubernamental.

iv. Los titulares de los permisos de radio comunitaria deben ser personas morales, integradas por representantes designados por la comunidad en forma plural y democrática. Serán causales de exclusión para pertenecer a una sociedad permisionaria:

- Desempeñarse como servidor público o ser miembro de cualquier jerarquía eclesiástica;

- Ser o haber sido en los últimos cinco años personal directivo de una empresa privada de radio y/o televisión;

- Ser representante oficial de algún partido político.

v. Debe establecerse un sistema tripartito de financiamiento para las radiodifusoras comunitarias, integrado de la siguiente forma: 
- Una dotación municipal, estatal y federal.

- Ingresos por patrocinios;

- Ingresos por donativos nacionales e internacionales, exentos de impuestos.

vi. Toda empresa permisionaria como radio comunitaria debe contar con un estatuto que establezca:

- Declaración de principios de quienes laboran en la radio comunitaria;

- Declaración de derechos y obligaciones de los usuarios, los comunicadores, los directivos y los patrocinadores de la radio comunitaria.

vii. La banda de operación, la frecuencia y la potencia de transmisión se determinarán atendiendo a las características geográficas de cada zona, garantizándose en todo caso que éstas aseguren la cobertura de la radio comunitaria en la zona establecida.

viii. Deben garantizarse fórmulas concretas de acceso ciudadano a la programación de la información, las cuales deberán ser plurales, diversas y tolerantes, y de ninguna manera restrictivas.

ix. Deben establecerse mecanismos concretos para el debido respeto de los derechos de la personalidad y del derecho de réplica, de tal manera que se garantice que en las radiodifusoras comunitarias todo aquel ciudadano que se sienta afectado por una información cuente con un espacio asegurado, con las mismas características y tiempo que aquel en que se le increpó.

x. La radiodifusora comunitaria debe estar exenta del pago de los derechos correspondientes a los tiempos del Estado, por su naturaleza especial y debido a que su programación es de servicio social y cultural.

xi. Las radiodifusoras comunitarias estarán en libertad de organizarse corporativamente como mejor les convenga para el total cumplimiento de sus funciones.

xii. El Estado debe garantizar a las radiodifusoras comunitarias su acceso individual y corporativo a sistemas de difusión satelital, público o privado, y a cualquier nueva tecnología, para establecer cadenas regionales, estatales, nacionales e internacionales para alcanzar eficazmente el cumplimiento de sus funciones. 
xiii. La programación de las radiodifusoras comunitarias debe ser congruente con sus fines.

xiv. Los requerimientos técnicos y de infraestructura por parte de la Secretaría de Comunicaciones y Transportes para autorizar el permiso de funcionamiento de una radiodifusora comunitaria no deben ser restrictivos, considerando su potencial económico y social. ${ }^{3}$

\subsection{En el plano de la sociedad civil}

1. Con apoyo de los sectores indígenas, se debe formar un frente cívico nacional de naturaleza plural y amplia que concentre a las principales organizaciones, movimientos e instituciones que han trabajado en los últimos años por la transformación del sistema de comunicación nacional, con el fin de que presionen políticamente para que se logre la aplicación del derecho a la información y la democratización de los medios de difusión en nuestro país. La primera acción de dicho frente deberá ser la organización de un Congreso Nacional de la Sociedad Civil para discutir con el Estado y el Poder Legislativo la renovación del vencimiento de las próximas concesiones de televisión y la distribución del nuevo espacio radioeléctrico en el país.

En este evento se deberán considerar, con especial atención, las propuestas de los grupos indígenas sobre los medios de comunicación y cultura presentadas en los acuerdos de San Andrés Larráinzar, para incorporarlas a la propuesta global.

2. Las comunidades indígenas deben exigir permanentemente a sus legisladores representantes en el Congreso de la Unión que presionen legislativamente para ser incluidos dentro de la legislación del derecho a la información.

3. Los sectores indígenas deben exigir a los partidos políticos que incluyan en sus plataformas ideológicas acciones concretas para la democratización de los medios de difusión, con el fin de que estos sectores puedan participar colectivamente a través de dichas tecnologías.

${ }^{3}$ La base de esta propuesta fue elaborada por el grupo de Organizaciones de la Sociedad Civil y el Centro Nacional de Comunicación Social (CENCOS) y presentada al equipo de transición del presidente Fox, en las áreas de política y cultura en diciembre del año 2000 (CEMEFI, 2000: 7-9). 
4. La sociedad civil organizada debe exigirle al Estado mexicano que cumpla internamente con los contenidos de los acuerdos que ha firmado en el ámbito internacional en el campo de la comunicación y la cultura, especialmente para permitir la expresión pluricultural de las comunidades indígenas. Esta realidad ofrece un enorme respaldo jurídico para avanzar en el proceso de pluralidad de las estructuras de comunicación y en el reconocimiento de derechos sociales informativos, pues ética y jurídicamente no se pueden adquirir compromisos internacionales y no aplicarlos nacionalmente.

5. Tomando en consideración que los medios de difusión se otorgan por concesiones, la sociedad civil debe exigir al nuevo gobierno que el Estado mexicano otorgue a la sociedad civil organizada una de las tres frecuencias reservadas al Estado y nuevos espacios en la ampliación del espectro electromagnético, para construir medios y franjas de información ciudadanas. Dentro de esta frecuencia, los pueblos indios deben tener un espacio de participación privilegiado.

6. Las comunidades indígenas deben presentar sistemáticamente a la Comisión de Radio, Televisión y Cinematografía (RTC) de las cámaras de diputados y senadores las conclusiones que se deriven de cada foro local, regional o nacional sobre la democratización de la comunicación y la aplicación del derecho a la información en su favor, y solicitar que éstas se tomen en cuenta en la formación de las políticas nacionales de gobierno.

\subsection{En el plano académico}

1. Los gobiernos municipales del país, especialmente del estado de Chiapas, deberán establecer convenios de capacitación en comunicación con las escuelas de información regionales, para que los grupos indígenas produzcan sus propios mensajes radiofónicos con base en sus necesidades de desarrollo.

2. Se deberán apoyar ampliamente a las escuelas radiofónicas, en todos sus niveles, para que éstas capaciten a los grupos indígenas en la generación de sus propios mensajes a partir de los intereses y necesidades de crecimiento y superación de sus comunidades. 


\section{Conclusiones}

Pensamos que con la consideración y aplicación de estas políticas informativas se podrán producir contextos más humanos para las etnias que los que ahora nos enmarcan en el país. De no transformar esta tendencia comunicativa salvaje, en el nuevo siglo tendremos en México centros y regiones económicas más interrelacionadas con la globalización, con más máquinas inteligentes, con mayores inversiones extrajeras, con más centros de información, con mayor incorporación de nuestra economía a los procesos de globalización, con más edificios modernos, con más automóviles, con más súper-carreteras, con nuevos centros de consumo, etcétera; pero también tendremos en el país conglomerados de comunidades humanas, especialmente indígenas, más destruidas que las que ahora conocemos, debido a la ausencia de una cultura cívico-democrática.

Por ello formulamos que el colaborar ahora desde los medios de comunicación y otras infraestructuras culturales para crear una base cultural de valores democráticos, ciudadanos y pluriculturales que rescaten la riqueza de las cosmovisiones indígenas no es romanticismo, ni mesianismo, ni voluntarismo político; sino exigencias elementales que se deben realizar para nuestra sobrevivencia humana como nación diversa. Si no actuamos hoy a través de los medios de comunicación transformando nuestras mentalidades para estar más conscientes de nuestros problemas nacionales y de nuestras alternativas de solución como nación, en el siglo XXI construiremos una sociedad enormemente más inhumana e inhabitable que la que ahora enfrentamos. Hoy en día los medios de comunicación tienen que ofrecer alternativas a los grupos indígenas como miembros de la nación del nuevo milenio.

Finalmente, para avanzar en la reforma del Estado mexicano en materia de información y construir una nueva política de comunicación nacional que rescate la presencia de los sectores indígenas se requiere, en primer término, la edificación de un nuevo orden comunicativo nacional, que supere el viejo modelo de información que no le da viabilidad al país, pues es un proyecto excluyente y no incluyente de las mayorías sociales y evita la maduración y el avance de nuestra sociedad, especialmente étnica. En segundo término, para construir el nuevo orden comunicativo es necesario que el Estado rescate su función rectora en el campo de la comunicación que ha abandonado o renunciado a 
ejercer desde hace algunas décadas, para delegarla a las fuerzas del mercado o a los grandes intereses políticos y privados. Ahora se requiere armar un nuevo proyecto de comunicación nacional basado en la participación de las comunidades, especialmente indígenas, que equilibre la dinámica salvaje que han alcanzado las fuerzas del mercado en el terreno de la cultura y la información. Y en tercer término, para concretizar este nuevo orden comunicativo se deberá elaborar un moderno marco normativo que delimite las vías equilibradas para que el espacio público que construyan los medios sea de naturaleza abierta y no cerrada, competitiva y no monopólica, incluyente y no excluyente, particularmente de los pueblos indios.

Sintetizando, podemos decir que, de no diseñarse las políticas de comunicación de los medios de información nacionales desde la perspectiva del reconocimiento y la resolución de los principales conflictos que obstaculizan el crecimiento de los grupos fundamentales del país -particularmente de los indígenas-, se volverá a vivir la profunda contradicción existente entre la cultura y comunicación nacional y el proyecto de desarrollo global que se ha arrastrado en las últimas décadas. Cada uno se disparará por senderos distintos: la cabeza social avanzará por un lado y el cuerpo por otro, aumentando rápidamente, con ello, la descomposición de la sociedad mexicana.

No podemos olvidar que la construcción de la nueva sociedad que demanda el México Profundo del siglo xxi, que ya se ha manifestado radicalmente a través de los levantamientos populares, requiere la producción de un nuevo eje cultural; y éste creemos que deberá girar en torno a la renovación de los medios de comunicación nacionales, especialmente de la televisión.

\section{Bibliografía}

III Conferencia Internacional Medios de Comunicación y Procesos Electorales (2000), "Diagnóstico y propuestas para la comunicación social del 2000”, Cámara de Diputados, Comisión de Radio, Televisión y Cinematografía, XuI Legislatura, Fundación Konrad Adenauer Stiffung, Universidad Iberoamericana, Universidad Autónoma Metropolitana, Federación Latinoamericana de Facultades de Comunicación Social, Consejo Nacional Para la Enseñanza e Investigación de las Ciencias de la Comunicación y Asociación Mexicana de Derecho a la Información, julio, México. 
III Congreso Nacional Indígena (2001), “Acuerdos Resolutivos del III Congreso Nacional Indígena, Mesa núm. 2-A y Mesa núm. 3", Comunidad indígena de Nurio, municipio de Michoacán (2 al 4 de marzo del 2001), Michoacán, documento web: <http:/www.laneta.apc.org/cni/ 3 cni.htm >.

v Conferencia Internacional Medios de Comunicación y Procesos Electorales (2002), "Los medios electrónicos en el marco de la reforma del Estado", H. Cámara de Diputados (XLIII Legislatura), Comisión de Comunicaciones y Transportes, Senado de la República, Fundación Konrad Adenauer Stiffung, Universidad Iberoamericana, Universidad Autónoma Metropolitana Xochimilco, Palacio Legislativo de San Lázaro, mayo, México.

Acción Social de los Jesuitas en México (1996), "La palabra. Derecho a los medios de comunicación y de una información verdadera, Derechos humanos. Derechos de los pueblos indios. Acuerdos del Congreso Nacional Indígena", (8 al 15 octubre), Nunca más un México sin nosotros, Congreso Nacional Indígena, México, Página web de Acción Social de los Jesuitas en México: < http://www. sjsocial.org/folletos/f_comu.htm >.

Aguirre Beltrán, Gonzalo (1983), Lenguas vernáculas, su uso y desuso en la enseñanza: la experiencia de México, Secretaría de Educación Pública, Ediciones de la Casa Chata 20, México.

Asociación Mexicana del Derecho a la Información (2000), Objetivos centrales. Documento Base, Asociación Mexicana del Derecho a la Información, enero, México.

Bodley, John H., (1982), Victims of progress, Mayfiel Publishing Company, Palo Alto.

Bonfil, Guillermo (1988), México Profundo: una civilización negada, Secretaría de Educación Pública, México.

CEMEFI (2000), "Propuestas para garantizar el acceso de la sociedad civil a la información y la comunicación", en Mesa de diálogo de las organizaciones de la sociedad civil con el 
equipo de transición del presidente electo Fox en las áreas social y política. Definición y propuestas para garantizar el acceso de la sociedad civil a los medios de comunicación. Elaboración de políticas públicas de comunicación (primera versión), noviembre, Centro Nacional de Comunicación Social (CENCOS), México, documento web: <http://www.cemefi.org/dialogos/documentos/ comunicación.cfm $>$.

Constitución Politica de los Estados Unidos Mexicanos (2001), Editorial Sista, México.

Díaz Polaco, Héctor (1991), Autonomía regional. La autodeterminación de los pueblos indios, Siglo XxI Editores, México.

Díaz Polaco, Héctor y Gilberto López Rivas (comps.) (1986), Nicaragua: Autonomía y Revolución, Juan Pablos Editor, México.

Esteinou Madrid, Javier (2002), “Diagnóstico y propuestas para la democratización de los medios de comunicación en México" en Seminario: "La Propiedad de los Medios y el Acceso Ciudadano en América Latina, Asociación Mundial para la Comunicación Cristiana, Observatorio Ciudadano de los Medios de Comunicación, Academia Mexicana de Derechos Humanos, Alianza Cívica, Asociación Mexicana por el Derecho a la Información, Comunicadores por la Democracia, Consejo de Educación de Adultos para América Latina, noviembre, México.

Florescano, Enrique (2001), Etnia, Estado y Nación. Ensayo sobre las identidades colectivas en México, Taurus, México.

FZLN (Frente Zapatista de Liberación Nacional) (1998), Material de estudio para la Consulta Nacional Sobre la Iniciativa de Ley Indígena de la Comisión de Concordia y Pacificación y por el Fin de la Guerra de Exterminio, Frente Zapatista de Liberación nacional, San Cristóbal Las Casas, Chiapas, documento web: <http://www.fzln.org.mx/archivo/dialogo/consulta/material.de.estudio.htm $>$. 
Gálvez Ruiz, Xóchitl (2001a), Entrevista con representantes indígenas, Centro Cultural El Carmen, Televisión Regional de Chiapas, San Cristóbal las Casas, Chiapas, 17 de enero, Página Internet de la Presidencia: <http://www. presidencia.gob.mx/? Orden $=$ Leer $\&$ Tipo $=$ DI\&Art $=319>$.

Gálvez Ruiz, Xóchitl (2001b), Programa Fox en vivo, Fox contigo, Cámara Nacional de la Radio y Televisión y Grupo ACIR, versión estenográfica, México, p. 2, Página Internet de la Presidencia de la República, <http://www. presidencia.gob. $\mathrm{mx} /$ ? $\mathrm{P}=16 \&$ Orden $=$ Leer $\&$ Tipo $=$ DI\&Art $=344>$.

Giménez, Gilberto (2000), "Identidades étnicas: estado de la cuestión", en Leticia Reina (coord.), Los retos de la etnicidad en los estados-nación del siglo XXI, CIESAS, INI, Miguel Ángel Porrúa, México.

Gobierno de México (2001), “Acuerdos de San Andrés Larráinzar", en: Chiapas con justicia y dignidad. Memoria de acuerdos, compromisos, acciones y obras, coordinación para el diálogo y la negociación en Chiapas, noviembre, México.

INI (Instituto Nacional Indigenista) (2000), Estatuto orgánico del Instituto Nacional Indigenista, México, Instituto Nacional Indigenista, (11/12/2000), documento web: <http:// www.ini.gob.mx/presenta.html>

Katz, Friedrich (comp.), (1990), Revuelta, rebelión y revolución: la lucha rural en México del siglo XVI al siglo XX, t. II, Era, México.

Kohn, Hans (1992), Historia del nacionalismo, Fondo de Cultura Económica (1949), Organización de las Naciones Unidas, Carta de la Tierra de los Pueblos Indígenas, aprobada en la conferencia de Kari Oca, mayo, México.

Ley Federal de Radio y Televisión y su Reglamento (2000), Comisión de Radio Televisión y Cinematografía (RTC), Cámara de Diputados, LVII Legislatura, México. 
Milenio Semanal (2000), núm. 152, 7 de agosto, México, Página web: <http:/www.milenio.com/frama.asp?url>.

Noticiario Cúpula Empresarial (s.f.), "Renovación del PRI, Entrevista con Francisco Labastida Ochoa", 22 de febrero, $1^{\text {a }}$ Edición, México.

OIT (Organización Internacional del Trabajo) (1997), “Convenio sobre pueblos indígenas y tribales, Organización Internacional del Trabajo (OIT), ILOLEX", en Base de datos sobre normas internacionales del trabajo, México, documento web: <http://ilolex.ilo.ch:1567/public/spanish/50normes/ infleg/ilospa/index.htm $>$ y <http://www.fzln.org.mx/dialogo/convenio.169.htm $>$ (19/3/1997).

Presidencia de la República (2000a), Iniciativa de Ley de Reforma Sobre los Derechos y Cultura Indígena (5 diciembre), México D.F., Presidencia de la República, Página Internet de la Presidencia de la República: <www.presidencia. gob.mx>

Presidencia de la República (2000b), Iniciativa de ley enviada por el Presidente Fox al H. Congreso de la Unión, 5 diciembre de 2000, Presidencia de la República, Gobierno de México, México, Página Internet de la Presidencia de la República: <www.presidencia.gob.mx>

Presidencia de la República (2001), "Fox en vivo, Fox contigo" (20 de enero), Programa radiofónico, Cámara Nacional de Radio y Televisión y Grupo ACIR, Presidencia de la República, México, Página Internet de la Presidencia de la República: <www.presidencia.gob.mx>.

Sandoval Forero, Eduardo Andrés y Juan Carlos Patiño (2000), Cartografía automatizada para la investigación de las regiones indígenas, Universidad Autónoma del Estado de México, Toluca.

Smith, Anthony (1993), The ethic origins of nations, The University of Chicago Press, Chicago. 
Solórzano Zinser, Javier (2001), “La televisión y los zapatistas”, Revista etcétera. Una ventana al mundo de los medios, s.p.i, México.

Stavenhagen, Rodolfo (2001), La cuestión étnica, El Colegio de México, México.

Stavenhagen, Rodolfo y Diego Iturralde (comps.) (1990), Entre la ley y la costumbre, Instituto Indigenista Interamericano, Instituto Interamericano de Derechos Humanos, México.

Toussaint, Florence (2001a), "TV Concierto de Televisa-TV Azteca”, en Revista Proceso, Semanario de información y análisis, núm. 1266, México.

Toussaint, Florence (2001b), "La marcha zapatista”, en Revista Proceso, Semanario de Información y Análisis, núm. 1270, México.

Vértiz, Columba (2001a), "El concierto por Chiapas. La unión Televisa/TV Azteca provoca el sarcasmo" en Revista Proceso, Semanario de información y análisis, núm. 1266, México.

Vértiz, Columba (2001b), "Un comercial de Viana entra al chacoteo político", en Revista Proceso, Semanario de información y análisis, núm. 1269, México.

Warman, Arturo (2001), “La propuesta de la Cocopa”, La Crónica de Hoy, 12 de diciembre, México.

Enviado: 18 de abril de 2002 Aceptado: 13 de junio de 2002 
